\title{
Application of topical tranexamic acid for clarity of vision in percutaneous endoscopic cervical discectomy: a retrospective study
}

\author{
Ke-Xiao Yu ${ }^{1, a}$, Santosh K Bashyal ${ }^{1, b}$, Lei Chu ${ }^{1}$, Liang Chen ${ }^{1}$, Zhong-Liang Deng ${ }^{1 *}$, Saroj K bashyal ${ }^{2}$ and Dristi Bashyal $^{3}$ \\ ${ }^{1}$ Department of Orthopaedics, The Second Affiliated Hospital, Chongqing Medical University, China \\ ${ }^{2}$ Universal dental hospital, Kalanki, Kathmandu, Nepal \\ ${ }^{3}$ Nepal Police hospital, Kathmandu, Nepal \\ a,b Equally contributed
}

\begin{abstract}
Objective: To describe novel topical application of tranexamic acid for clarity of vision in pPECD

Method/ Result: 7 patients showed no poor endoscopic vision, the age (35.86 \pm 6.09 vs $56.25 \pm 12.84)$, HB $(157.00 \pm 9.18$ vs $134.61 \pm 19.98)$, HCT (45.20 \pm 2.18 vs $40.03 \pm 5.28)$ in the 7 patients showed significant difference between other 57 patients $(\mathrm{p}<0.001) .57$ patients were treated with bipolar radiofrequency, the baseline of all the 57 patients showed no significant difference, proportion of osteoporosis patients in stop bleeding success group was significant less than that in the failed group ( $9.68 \%$ vs $36.42 \%, p=0.027)$. Success rate of used TXA no less than 3 min were significant higher than that used less than 3 min ( $<<0.001)$. The use times of bipolar radiofrequency in region B $(24.16 \pm 7.27)$ showed significant different between region A $(1.84 \pm 0.88)$ and region $\mathrm{C}(5.02 \pm 2.33)(\mathrm{p}<0.001)$
\end{abstract}

Conclusion: Topical application of tranexamic acid $(10 \mathrm{ml}$ TXA concentration $1 \mathrm{~g} / \mathrm{L})$ is effective, safe method for the patients for at least 3 minute where bleeding doesn't stop after 3 minutes when bipolar radiofrequency being used. Topical TXA is a supplement of hemostatic method in PECD

\section{Introduction}

The posterior percutaneous endoscopic cervical discectomy (pPECD) is considered as one of the most successful minimal invasive spine surgery for cervical disc herniation [1-5]. The concept of pPECD is endoscopic decompression of cervical disc herniation through the complete posterior percutaneous approach. Under Endoscopic Cervical spine surgery, there is risk of injury to vessels especially in epidural vessels or venous sinus in bone tissue which can be minimized by proper visualization and clarity of vision [4,6-10]. The quality of endoscopic Images and the progression of operative procedure will be hindered by intra-operative bleeding [11]. During early practice (2011) of pPECD in our department, we encountered challenges in 2 cases where we couldn't stop the continuous bleeding with the help bipolar radiofrequency and saline water irrigation although other parameters were normal and had to stop further steps. Later patients agree and got consent for ACDF and managed. One of the method to reduce bleeding during operative procedure is to increase the pressure of saline water irrigation but can cause risk of myelon damage and temporary postoperative headache [12].

Tranexamic acid (TXA) is an anti-fibrinolytic agent that acts by blocking the lysine ding sites on plasminogen molecules, inhibiting the formation of plasmin. Topical TXA has gained recent interest in orthopedics surgery because of its demonstrated benefit in several clinical trials $[1-3,5,13]$.

To the best of our knowledge, no related study of PPECD has been performed in the hemostasis of topical application of TXA (injected into the operative field) for reducing intraoperative epidural bleeding and proper visualization and clarity. In this retrospective study, we will report the effectiveness and safety of topical use of TXA, and try to analysis the reasons of intraoperative bleeding.

\section{Materials and methods}

\section{Patient population}

From Oct. 2015 to Dec. 2016, 64 consecutive patients were treated with primary posterior approach of percutaneous endoscopic cervical discectomy.

\section{Patient selection}

The inclusion criteria were as follows: (1) failed conservative therapy of at least 4 weeks or symptom deterioration to the extent of being unbearable, (2) neurological symptoms consistent with the preoperative magnetic resonance image and computed tomography myelography, (3) single level posterolateral or paramedian disc herniation

Correspondence to: Zhong-liang deng, Department of Orthopaedics, The Second Affiliated Hospital, Chongqing Medical University, No.76 Linjiang Road, DistrictYuzhong, Chongqing, 400010, China, Tel: +8613608367586

Key words: topical application, tranexamic acid, $P P E C D$, intraoperative bleeding Received: October 02, 2017; Accepted: October 24, 2017; Published: October 27, 2017 


\section{Exclusion criteria included:}

(1) revisions

(2) segmental instabilities or deformities

(3) cervical vascular malformation

(4) isolated neck pain for which the cause could not be determined by MRI or computed tomography myelography

(5) history of neck trauma

(6) hemoglobin disorders

(7) coagulation disorders

(8) contraindications for the use of TXA.

All the surgeries were performed in one institutional hospital by one Orthopedic-spinal surgeon. All patients were in the prone position under general anesthesia, the height between saline bags and operating table was 60 centimeters.

\section{Operative Technique}

In all cases surgeries were performed by previously described conventional pPECD techniques.

The patient was placed in a prone positon under general anesthesia and the neck in slight flexion, the head was fixed with Cranial Stabilization System (German, DORO). The operations were performed under electro-neurophysiology monitoring. An 8-mm transverse incision was made above the fact joint on the pathological side, a blunt puncture needle was inserted through the incision onto the laminae of the target level. Insertion of the dilator via the needle, and insertion of the endoscope sheath via the dilator. Removal of the dilator and the puncture needle, then insert the endoscope. The further procedure were performed under endoscopy, the clarity of operation field is depend on continuous irrigation with $0.9 \%$ saline solution. Use bipolar radiofrequency to clean the tissues under endoscopy and exposure the adjacent vertebral laminae and the medial part of ipsilateral facet joint between them, which formed a V-point structure. Then using an endoscopic high speed burr and kerrison to resect the bone of the laminae at the medial joint parts and the ligamenta flava until the dural sac or nerve root was identified. Then mobilized the nerves, and resected the posteriorly protruded nucleus pulposus. When the free mobilization of the nerve root can be confirmed, the decompression is adequate. Then removal of all the instruments (Figure 1).

\section{Regional division of intraoperative bleeding}

The anatomy of pPECD is divided into 3 regions: the region from skin to the posterior margin of lamina is region $A$, the lamina to the posterior margin of thecal sac and nerve roots is region $\mathrm{B}$, the thecal sac and nerve roots to the posterior margin of cervical vertebral is region C (Figure 2).

\section{Endoscopic vision definition classification}

In order to describe the clarity of the endoscopic vision and evaluated the effective of TXA, clarity of vision were classified into four grades (Figure 3).

Excellent: The clarity of vision is excellent, we can easily distinguish the structures under endoscope such as the texture of the muscle fibers, epidural fat, blood vessels, bone tissue, dura sac or nerve root in the entire screen.
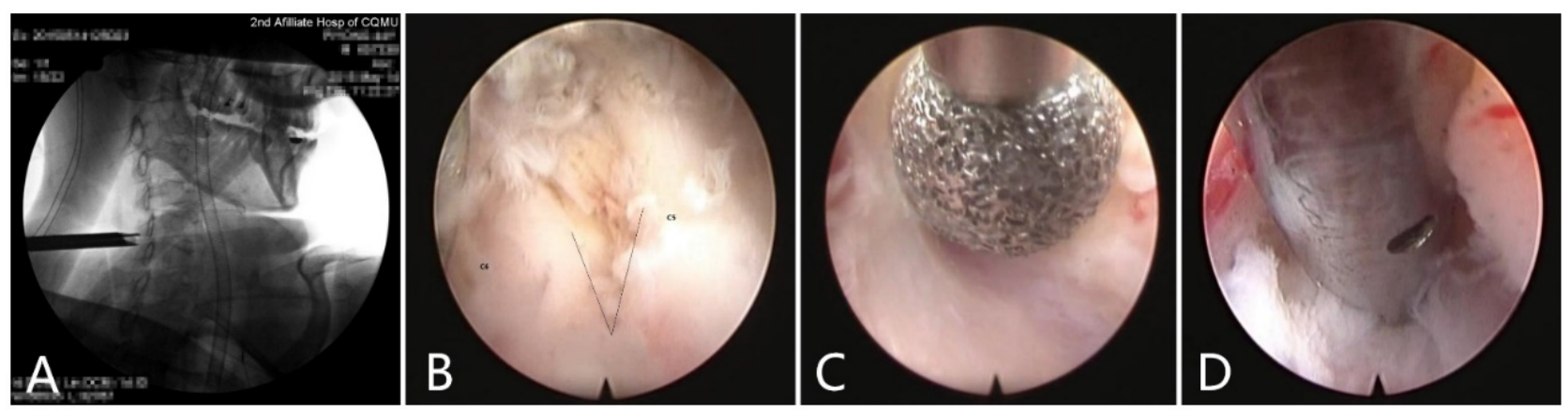

Figure 1. Fluoroscopy with the intraoperative $\mathbf{C}$-arm shows that working systems of posterior endoscopic cervical discectomy (A). The intraoperative view shows that the interlaminar window between C5 and C6 is exposure (B) and opened stepwise using the burr (C). The step of extract the nucleus pulposus tissue in endoscopy.
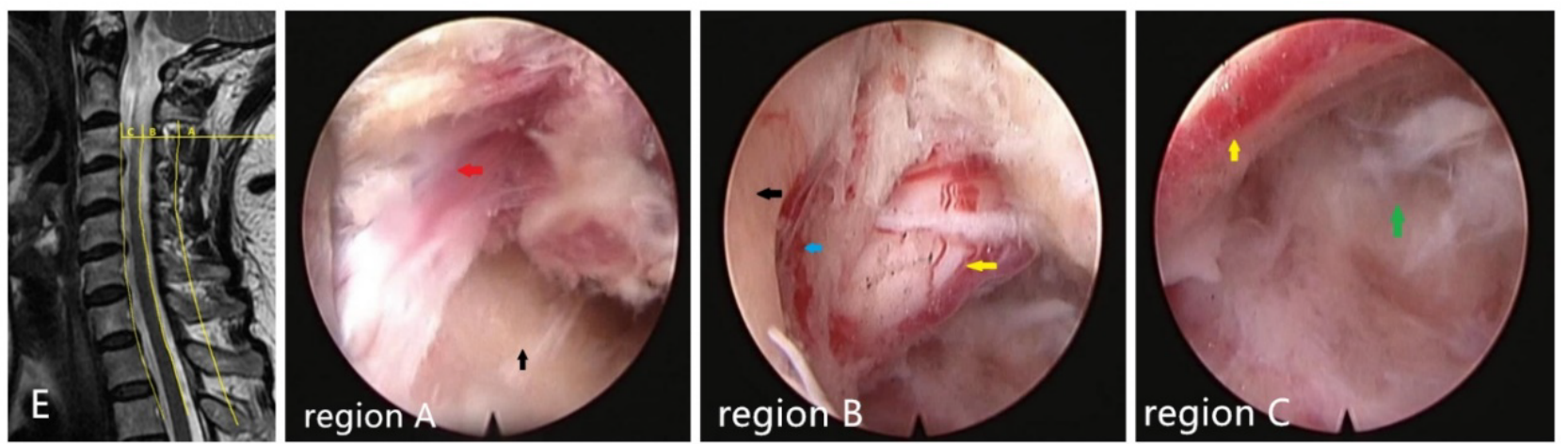

Figure 2. The sketch map of cervical anatomy region (E) and the structures of muscle (red arrow), laminae(black arrow), epidural vessels (blue arrow), C5/6 nerve root (yellow arrow) and nucleus pulposus (green arrow) in endoscopy of each region 

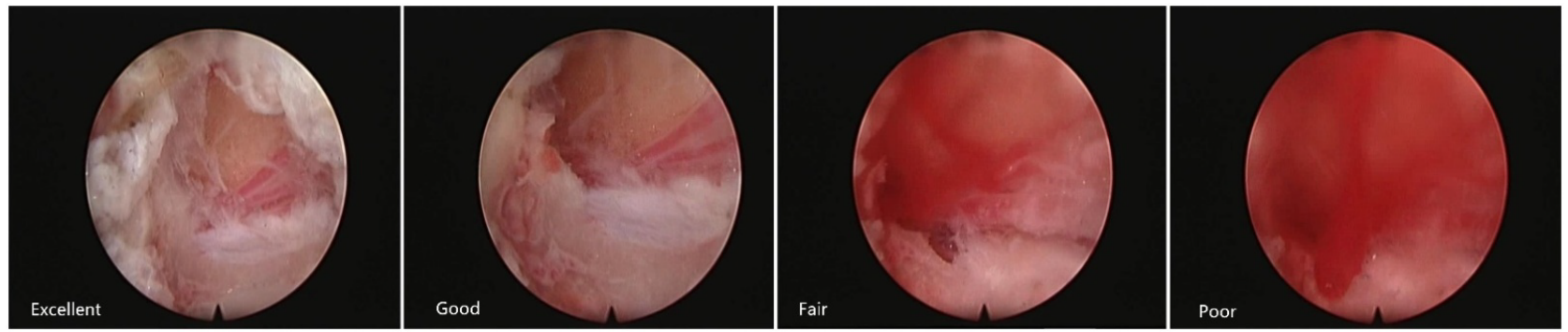

Figure 3. The four grades of endoscopic vision.

Good: The clarity of vision is good, although the color of screen is a little reddish due to invisible bleeding, we can distinguish the structures under endoscopy, and the progress of operation will not be impaired.

Fair: The color of screen turn to deep red, visible bleeding occur, we can't identify the texture of endoscopic structures. The structures could be identified hardly but potential risks in progress or operation.

Poor: The color of screen become dark red, significant bleeding occur, we can't see any structures under endoscopy, the progress of operation will be hindered.

\section{Method of topical application of tranexamic acid}

When Intra-operative bleeding is encountered during pPECD operation, at first we use bipolar radiofrequency to stop bleeding if the vision and clarity is poor. If it didn't stop within $3 \mathrm{~min}$, we inject $10 \mathrm{ml}$ of Tranexamic acid concentration of $1 \mathrm{~g} / \mathrm{L}$ topically into the operating filed via endoscopic water inlet passing the irrigation solution .We divided the patients randomly into 5 groups according to the use of TXA time as 1, 2, 3, 4, 5 min group to study and report the effectiveness, safety of topical used of TXA. Each $10 \mathrm{ml}$ of TXA concentration of $1 \mathrm{~g} / \mathrm{L}$ were added to use it if vision and clarity was poor (Figure 4).

\section{Measurement and Statistical Analysis}

In all the patients' blood parameters like red blood cell count (RBC), White blood cell count(WBC), hemoglobin(Hb),hematocrit(Hct), platelet count, $\mathrm{APTT}(\mathrm{sec})$ were done and postoperative complication like Deep vein thrombosis (DVT), Pulmonary embolism (PE) and other were observed. All the patients were screened for osteoporosis by bone mineral density using Dual energy X-ray absorption (DXA). Those numbers of patients diagnosed as osteoporosis was compared in bipolar radiofrequency intervention group.

The time duration for the use of bipolar radiofrequency used to coagulate vessels and soft tissues for clear exposure were recorded in each region by 2 observers. The observers were experienced orthopedic spine surgeons who were familiar with the procedure of PPECD and the structures under endoscopy.

All data management and statistical analysis were performed with SPSS version 19.0 software $p$ values calculated using independent t-test, Person chi-square test,Fisher exact test, paired t-test and oneway ANOVA. The probability of $\mathrm{p}$ value less than .05 was considered as statistical significance.

\section{Result}

In our study group out of 64 patients, 7 had no poor visualization till operation completed, whereas 57 showed poor vision .In 31 cases bipolar radiofrequency were successfully to stop bleeding whereas in 26 cases failed. According to Grading system of endoscopic vision successfully bleeding stop mean excellent, good or fail however hemostasis failed mean poor grading. In this cases we use TXA to stop bleeding. According to priority of admission these 26 patients were divided into 5 groups according to the use of TXA time as 1, 2, $3,4,5$ min group. In the 3, 4, $5 \mathrm{~min}$ groups, all patients hemostasis successful, showed no poor vision. In the 1 min group, there was 1 patient hemostasis successful. In the 2 min group, there were 3 patients hemostasis successful. All the failed patients both in 1 min group and 2 min group were received more addition concentration TXA use and all of these cases hemostasis successfully (Figure 4).

In the none intervention group we find the age $(35.86 \pm 6.09$ vs $56.25 \pm 12.84), \mathrm{HB}(157.00 \pm 9.18$ vs $134.61 \pm 19.98)$, HCT ( $45.20 \pm 2.18$ vs $40.03 \pm 5.28)$ in the 7 patients showed statistical significance difference between the other 57 patients ( $\mathrm{p}<0.001$ Table 1$)$.

In the bipolar radiofrequency intervention group, the baseline of all the 57 patients showed no significant difference, but the proportion of osteoporosis patients in the success group was significant less than the proportion in failed group ( $9.68 \%$ vs $36.42 \%, \mathrm{p}=0.027$, Table 2 ).

The baseline of topical application of TXA intervention groups showed no significant difference. The baseline of TXA intervention groups showed no significant difference, the success rate showed significant different between the groups that less than $3 \mathrm{~min}$ and not less than $3 \min (p<0.001$, Table 3$)$.

The usage of bipolar radiofrequency in region B $(24.16 \pm 7.27)$ showed significant different between region $\mathrm{A}(1.83 \pm 0.88)$ and region $C(5.02 \pm 2.33)(p<0.001$, Figure 5). The Postoperative complication such as nerve root or spinal cord injury, DVT events, PE events, hematoma, headache and infection were not found.

\section{Discussion}

The clarity of operative field is the basic of foundation for effective surgery so any bleeding points should be coagulated. If the grade of endoscopic vision is fair or more clear, bleeding points can be identified easily, so it's not hard to be stopped by bipolar radiofrequency. However, in case of poor the grade of endoscopic, it is a challenge to search for bleeding points and the vision is very poor. At this time, we usually use the head of the bipolar radiofrequency frequency try to touch every possible bleeding points: use the head of bipolar radiofrequency, press a possible bleeding point, wait for several seconds, if the vision turned clarity, then we can confirm that it is the bleeding point, in this way the bleeding could be stop. If the vision turn not clarity, we should change to press other places. It is less likely to injury nerves under intraoperative electrophysiological monitoring, but there is still a potential risk. If no electrophysiological monitoring, risk of nerve damage will be higher [14]. In order to solve this problem, we try to find out hemostatic drugs which can be used topically to stop bleeding. After reviewing the literatures, we decided to use tranexamic acid, it is relatively inexpensive and does not appear to cause any 


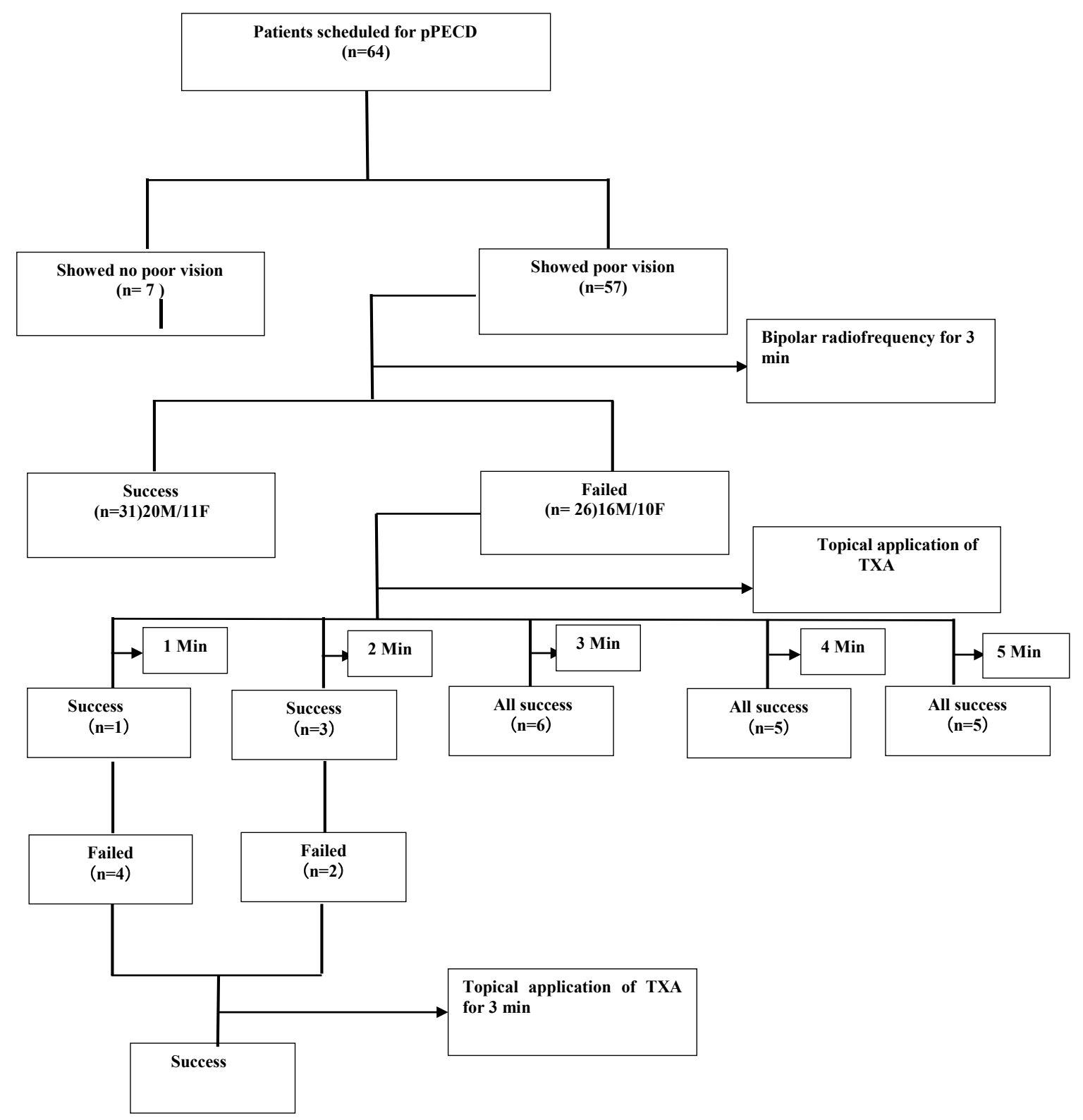

Figure 4. Flow diagram of patients treating

Table 1. Compare the baseline of no poor view group and poor view group.

\begin{tabular}{|c|c|c|c|c|}
\hline & $\begin{array}{c}\text { No poor view } \\
(\mathbf{n}=7)\end{array}$ & $\begin{array}{c}\text { Poor view } \\
(\mathbf{n}=\mathbf{5 7})\end{array}$ & $\mathbf{p}$ & $\mathbf{t}$ \\
\hline Male sex & $6(85.71 \%)$ & $36(63.16 \%)$ & 0.406 & - \\
\hline Age $^{\mathrm{a}}(\mathrm{y})$ & $35.86 \pm 6.09$ & $56.25 \pm 12.84$ & $<0.001$ & -4.123 \\
\hline $\mathrm{BMI}^{\mathrm{a}}(\mathrm{kg} / \mathrm{m} 2)$ & $23.60 \pm 2.10$ & $24.42 \pm 3.78$ & 0.578 & -0.560 \\
\hline $\mathrm{RBC}^{\mathrm{a}}(\times 109)$ & $5.05 \pm 0.35$ & $4.39 \pm 0.55$ & 0.003 & 3.070 \\
\hline $\mathrm{HB}^{\mathrm{a}}(\mathrm{g} / \mathrm{L})$ & $157.00 \pm 9.18$ & $134.61 \pm 19.98$ & $<0.001$ & 5.129 \\
\hline $\mathrm{HCT}^{\mathrm{a}}(\%)$ & $45.20 \pm 2.18$ & $40.03 \pm 5.28$ & $<0.001$ & 4.786 \\
\hline $\mathrm{PLT}^{\mathrm{a}}(\times 109)$ & $204.86 \pm 38.62$ & $195.54 \pm 61.09$ & 0.696 & 0.392 \\
\hline APTT $^{\mathrm{a}}(\mathrm{sec})$ & $35.04 \pm 3.66$ & $36.66 \pm 3.71$ & 0.279 & -1.092 \\
\hline
\end{tabular}

Abbreviations: BMI, body mass index; RBC: red blood count; HB: hemoglobin; Hct: hematocrit; PLT: platelet count APTT: activated partial thromboplastin time; P values calculated using Fisher's exact test and independent t-test.

a The values are given as mean \pm standard deviation.
Table 2. Compare the baseline of usedbipolar radiofrequency success group and failed group.

\begin{tabular}{|c|c|c|c|c|}
\hline & $\begin{array}{c}\text { Success } \\
(\mathbf{n = 3 1})\end{array}$ & $\begin{array}{c}\text { Failed } \\
(\mathbf{n = 2 6})\end{array}$ & $\boldsymbol{p}$ & $\mathbf{t}$ \\
\hline Male sex & $20(64.52 \%)$ & $16(61.54 \%)$ & 0.816 & - \\
\hline $\mathrm{Age}^{\mathrm{a}}(\mathrm{y})$ & $55.26 \pm 12.94$ & $57.42 \pm 12.87$ & 0.531 & -6.31 \\
\hline $\mathrm{BMI}^{\mathrm{a}}(\mathrm{kg} / \mathrm{m} 2)$ & $24.17 \pm 4.08$ & $24.72 \pm 3.44$ & 0.593 & -0.538 \\
\hline $\mathrm{RBC}^{\mathrm{a}}\left(\times 10^{9}\right)$ & $4.40 \pm 0.50$ & $4.37 \pm 0.62$ & 0.849 & 0.191 \\
\hline $\mathrm{HB}^{\mathrm{a}}(\mathrm{g} / \mathrm{L})$ & $135.87 \pm 19.72$ & $133.12 \pm 20.56$ & 0.608 & 0.515 \\
\hline $\mathrm{HCT}^{\mathrm{a}}(\%)$ & $40.17 \pm 5.03$ & $39.86 \pm 5.66$ & 0.824 & 0.224 \\
\hline $\mathrm{PLT}^{\mathrm{a}}\left(\times 10^{9}\right)$ & $204.52 \pm 65.98$ & $184.85 \pm 54.00$ & 0.229 & 1.216 \\
\hline $\mathrm{APTT}^{\mathrm{a}}(\mathrm{sec})$ & $36.76 \pm 3.93$ & $36.55 \pm 3.50$ & 0.830 & 0.216 \\
\hline $\mathrm{OP}$ patients & $3(9.68 \%)$ & $9(34.62 \%)$ & 0.0027 & - \\
\hline
\end{tabular}

Abbreviations: BMI, body mass index; RBC: red blood count; HB: hemoglobin; Hct: hematocrit; PLT: platelet count APTT: activatedpartial thromboplastin time; OP: osteoporosis; $P$ values calculated using Person chi-square, Fisher's exact test andindependent t-test.

a The values are given as mean \pm standard deviation. 
Table 3. Compare the baseline of each group that used TXA.

\begin{tabular}{|c|c|c|c|c|c|c|c|}
\hline & 1min group & $2 \min$ group & $3 \mathrm{~min}$ group & 4min group & $5 \mathrm{~min}$ group & $p$ & $\mathbf{F}$ \\
\hline Male sex & $2(40 \%)$ & $3(60 \%)$ & $4(67 \%)$ & $3(60 \%)$ & $4(80 \%)$ & $0.425^{\mathrm{b}}$ & - \\
\hline Age ${ }^{a}(y)$ & $57.80 \pm 6.76$ & $64.00 \pm 13.45$ & $52.50 \pm 14.58$ & $50.80 \pm 9.15$ & $63.00 \pm 16.57$ & 0.366 & 1.137 \\
\hline BMI ${ }^{a}(\mathrm{~kg} / \mathrm{m} 2)$ & $27.54 \pm 3.41$ & $24.68 \pm 3.79$ & $24.35 \pm 3.32$ & $23.02 \pm 2.98$ & $24.06 \pm 3.33$ & 0.319 & 1.256 \\
\hline $\mathrm{RBC}^{\mathrm{a}}\left(\times 10^{9}\right)$ & $4.13 \pm 0.82$ & $4.32 \pm 0.56$ & $4.57 \pm 0.55$ & $4.20 \pm 0.71$ & $4.63 \pm 0.52$ & 0.658 & 0.613 \\
\hline $\mathrm{HB}^{\mathrm{a}}(\mathrm{g} / \mathrm{L})$ & $123.40 \pm 23.31$ & $134.00 \pm 16.08$ & $130.83 \pm 25.28$ & $133.40 \pm 22.61$ & $144.40 \pm 15.65$ & 0.642 & 0.637 \\
\hline $\mathrm{HCT}^{\mathrm{a}}(\%)$ & $37.36 \pm 6.31$ & $39.34 \pm 4.85$ & $39.63 \pm 6.98$ & $39.80 \pm 6.17$ & $43.20 \pm 3.97$ & 0.631 & 0.654 \\
\hline PLT a $^{\text {a } \times 109)}$ & $169.80 \pm 50.57$ & $176.60 \pm 52.53$ & $193.00 \pm 64.53$ & $177.60 \pm 45.03$ & $205.60 \pm 67.79$ & 0.856 & 0.328 \\
\hline $\mathrm{APTT}^{\mathrm{a}}(\mathrm{sec})$ & $35.92 \pm 2.99$ & $37.72 \pm 3.54$ & $37.75 \pm 3.16$ & $34.64 \pm 4.82$ & $36.46 \pm 3.23$ & 0.605 & 0.694 \\
\hline Success rate & $20 \%(1 / 5)$ & $60 \%(3 / 5)$ & $100 \%(6 / 6)$ & $100 \%(5 / 5)$ & $100 \%(5 / 5)$ & $\square 0.001^{\mathrm{b}}$ & - \\
\hline
\end{tabular}

Abbreviations: BMI, body mass index; RBC: red blood count; HB: hemoglobin; Hct: hematocrit; PLT: platelet count APTT: activated partial thromboplastin time; P values calculated using one-way ANOVA.

a The values are given as mean \pm standard deviation.

$\mathrm{b}$ it means the difference is compared between groups that less than $3 \mathrm{~min}$ and not less than $3 \mathrm{~min}$.

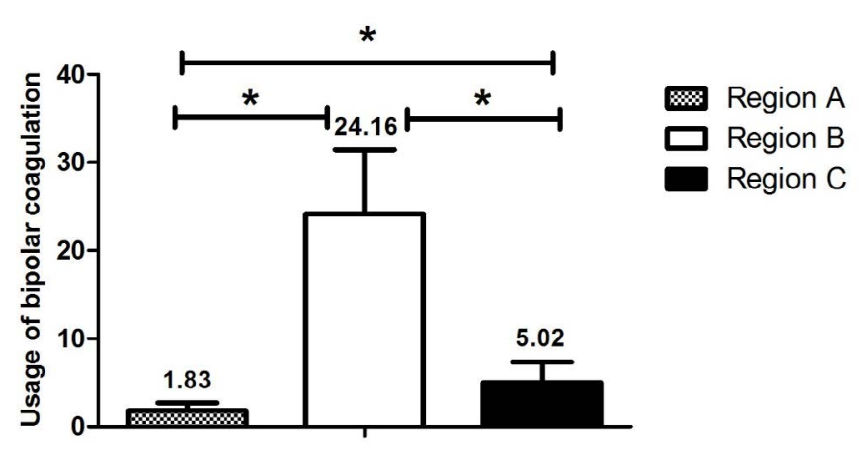

Anatimy regions

Figure 5. The number of bipolar radiofrequency usage in each anatomy region. The asterisks indicate values that were significantly different between the groups, $\mathrm{P}<0.001, \mathrm{P}$ values calculated using paired t-test.

significant untoward side effects [15-17]. Topical use of TXA has no electro- physical and histological effect on sciatic nerve to one month in rat study and it was concluded that use of topical TXA is effective without causing neurological changes [18].

The study of 40 Patients where intra-articular TXA used during total knee arthroplasty concluded that topical use of TXA is effective to reduce blood loss. The single use of topical TXA is found to be safer compared to intravenous TXA [19].

Tranexamic acid binds to sites on plasminogen to prevent binding to fibrin and it is subsequent activation to plasmin which would otherwise result in breakdown of fibrin to degradation products. Topical application of tranexamic acid are widely in clinical hemostasis such as total hip replacement (THR), total knee arthroplasty (THA) or epistaxis according to the safety and effectiveness $[1-3,5,13,20]$.

In one of the study it is found that during joint surgery ,bleeding cause improper visualization and tissue identification is difficult to further progression of surgery and the topical use of TXA helped to stop bleeding and secondly clarity of the vision in open surgery [2].

In our study, there were $11 \%$ (7/67) patients didn't showed poor grade of endoscopic vision, the age, HB and HCT in these patients showed significant different than that in patients who showed poor vision (Table 1). This is the probably reason why the vision was clear. However, 89\% (57/64) pPECD patients suffer from intraoperative bleeding which resulted in poor grade vision, though the bipolar radiofrequency were usedas long as $3 \mathrm{~min}$, there are still 46\% (26/57) patients couldn't hemostasis successfully. For these patients, TXA were topical used to stop bleeding, we find that it will get better effectiveness if the use time is not less than $3 \mathrm{~min}$ (Figure 1). The reason may be the blood clot can formatted strength enough to stop bleeding after 3 min. Compared with the success and failed proportion of osteoporosis patients in bipolar radiofrequency intervention groups, osteoporosis may result in poor effectiveness of bipolar radiofrequency (Figure 2). The reason may be the bone tissue of these patients were too fragile to damage, even if surgical instruments such as endoscopic high speed burr and kerrsion are used correctly, there are adjacent bone tissue be resected which may lead to bleeding. There were no complications such as deep vein thrombosis (DVT) events, pulmonary embolism (PE) events or nerve injury occurred.

In the comparative study between intravenous verse topical TXA in primary total hip replacement surgery, combined use of both was found to be effective in decreasing hemostasis without risk of complication like DVT,PE and wound infection. Those patients having high risk of thromboembolic events, topical TXA can be the choice [21].

The quality of images under endoscope is important for pPECD, with a high clarity images the operation can progress smoothly [12]. In the procedure of pPECD, the visible bleeding usually occur at the steps of exposure the $\mathrm{V}$-point structure, resect the bone of the laminae and ligament flava, mobilization the nerves in order to extract the protruded nucleus pulposus. In one of the study about the topical application in spinal surgery concluded that blood loss can be effectively reduced compared with intravenous TXA. However intravenous TXA is efficacious for reducing blood loss in spinal surgery. The literature related to topical TXA in spinal surgery is very less and need further clinical researches and alterative way for surgical site blood loss [22].

Region A is the first anatomy region of PPECD, with continue saline irrigation, this region is not easy to bleed, even though there is any bleeding points, the vessels in this region are easily to be coagulated by bipolar radiofrequency, usage of bipolar radiofrequency in this region is less (Figure 3). Region B is the second anatomy region of pPECD, when the bone of lamina are resect through endoscopic high speed burr and kerrison, the venous sinus in the bone tissueand epidural vessels which will lead to severe bleeding are easily to be injured, as soon as these vessels break, the grade of endoscopic vision will turn to poor rapidly probably. What's more, the epidural vessels are very close to the inner side of the lamina, epidural vessels are easily to be injured when the lamina are resected. In region C, there are some little vessels on the surface of nerves, some operation may injured these vessels. In conclude, the vessels in region B is more likely to be injured, the used times of bipolar radiofrequency in this region were also significant more than that in region A or B (Figure 3). 
In case of elderly osteoporosis patients during pPECD procedure,laminae is resected to make further space reach disc ,spinal cord ,there is most likely to bleed. The intra-operative bleeding need to be stop for further visualization during surgery. The topical application of tranexamic acid (10 ml TXA concentration $1 \mathrm{~g} / \mathrm{L})$ is effective, safe method for the patients for at least 3 minute where bleeding doesn't stop after 3 minutes when bipolar radiofrequency being used. The bipolar radiofrequency is still the most significant hemostatic method, however the use of TXA is a supplement of hemostasis to make the vision clarity enough to use bipolar radiofrequency safely especially in poor vision.

\section{The strength of this current study}

First, the study design is carefully, so the results is reliable. Second, this is the first time to report intraoperative bleeding in PPECD, with the help of endoscopic vision definition classification and count the usage of bipolar radiofrequency in PPECD, we could be able to evaluate bleeding relatively accurately. Third, it is the first time to report topical application of tranexamic acid in PPECD, the preliminary conclusion is that TXA should be used at least $3 \mathrm{~min}$ then we could got a good effectiveness.

\section{Limitation}

This is limited to retrospective study. The secondary limitations of our research are single surgeon and institution, the sample size of TXA application is small. Thus, this research conclusions should be verified at multi centers and quantitative study should be performed. In addition, TXA is only a kind of anti-fibrinolytic drugs, if we use some human thrombin, the clotting time may be shorter.

\section{Conflict of Interest}

All authors have no conflicts of interest to report. None of the authors of the manuscript received any remuneration. Further, the authors have not received any reimbursement or honorarium in any other manner. The authors are not affiliated in any manner with any remuneration.However, all the authors are members of the Spine unit of orthopedic department of second hospital of Chongqing medical university and practicing interventional pain physicians .

\section{Funding}

The authors wish to disclose and thank the sponsor of the study .This work was partially supported by Chongqing Geriatric Medicine Clinical research center(No.CSTC2015yfpt_gejsyjzx120019 for ZL Deng).They had no influence or interference after the protocol was designed.

\section{References}

1. Alshryda S, Mason J, Sarda P, Nargol A, Cooke N, et al. (2013) Topical intraarticular tranexamic acid reduces blood loss and transfusion rates following total hip replacement: a randomized controlled trial TRANX-H. J Bone Joint Surg Am 95: 19691974. [Crossref]

2. Alshryda S, Sukeik M, Sarda P, Blenkinsopp J, Haddad FS, et al. (2014) A systematic review and meta-analysis of the topical administration of tranexamic acid in total hip and knee replacement. Bone Joint J 96-96B: 1005-1015. [Crossref]

3. Alshryda S, Mason J, Vaghela M, Sarda P, Nargol A, et al. (2013) Topical (intraarticular) tranexamic acid reduces blood loss and transfusion rates following total knee replacement: a randomized controlled trial TRANX-K. J Bone Joint Surg Am 95: 1961. [Crossref]

4. Birkenmaier C, Komp M, Leu HF, Wegener B, Ruetten S (2013) The current state of endoscopic disc surgery: review of controlled studies comparing full-endoscopic procedures for disc herniations to standard procedures. Pain Physician 16: 335-344. [Crossref]
5. Georgiadis AG, Muh SJ, Silverton CD, Weir RM, Laker MW (2013) A prospective double-blind placebo controlled trial of topical tranexamic acid in total knee arthroplasty. J Arthroplasty 28:78-82. [Crossref]

6. Ruetten S, Komp M, Merk H, Godolias G (2007) A new full-endoscopic technique for cervical posterior foraminotomy in the treatment of lateral disc herniations using 6.9$\mathrm{mm}$ endoscopes: prospective 2-year results of 87 patients. Minim Invasive Neurosurg 50: 219-226. [Crossref]

7. Ruetten S, Komp M, Merk H, Godolias G (2008) Full-endoscopic cervical posterior foraminotomy for the operation of lateral disc herniations using 5.9-mm endoscopes: a prospective, randomized, controlled study. Spine (Phila Pa 1976) 33: 940-948. [Crossref]

8. Neilipovitz DT1 (2004) Tranexamic acid for major spinal surgery. Eur Spine J 13 Suppl 1: S62-65. [Crossref]

9. Xiao CL, Chun MH, Zhong CF, Deng GB, Liang RW (2016) Full-Endoscopic Procedures Versus Traditional DiscectomySurgery forDiscectomy: A Systematic Review and Meta-analysis of Current Global Clinical Trials. Pain Physician 19: 103118. [Crossref]

10. Yong A (2016) Percutaneous endoscopic cervical discectomy using working channel endoscopes. Expert Rev Med Devices 13: 601-610. [Crossref]

11. Wen CT (2011) Anterior Percutaneous Endoscopic Cervical Discectomy for Cervical Intervertebral Disc Herniation: Outcome, Complications, and Technique. J Spinal Disord Tech 24: 421-431. [Crossref]

12. Jun SY, Chu L, Chen L, Chen F, Ke ZY, et al. (2014) Anterior or Posterior Approach of Full-Endoscopic Cervical Discectomy for Cervical Intervertebral Disc Herniation? Spine (Phila Pa 1976) 39: 1743-1750. [Crossref]

13. Yue C, Kang P, Yang P, Xie J, Pei F (2014) Topical application of tranexamic acid in primary total hip arthroplasty: a randomized double-blind controlled trial. $J$ Arthroplasty 29: 2452-2456. [Crossref]

14. Resnick DK, Anderson PA, Kaiser MG, Groff MW, Heary RF, et al. (2009) Electrophysiological monitoring during surgery for cervical degenerative myelopathy and radiculopathy. $J$ Neurosurg Spine 11:245-252. [Crossref]

15. Lemaire R1 (2008) Strategies for blood management in orthopaedic and trauma surgery. J Bone Joint Surg Br 90: 1128-1136. [Crossref]

16. Mannucci PM1, Levi M (2007) Prevention and treatment of major blood loss. N Engl J Med 356: 2301-2311. [Crossref]

17. McMillan MR (2013) Full endoscopic, posterior cervical foraminaotomy and discectomy for cervical radiculopathy. In: Lewandrowski KU, Lee SH, Iprenburg M, editors. Endoscopic spinal surgery. London: JP Medical 49-56.

18. Ran S, Phuc D, Michele L (2015) Topical Tranexamic Acid Does Not Affect Electrophysiologic or Neurovascular Sciatic Nerve Markers in an Animal Model. Clin Orthop Relat Res 473: 1074-1082. [Crossref]

19. Soni A, Saini R, Gulati A, Paul R, Bhatty S, et al. (2014) Comparison between intravenous and intra-articular regimens of tranexamic acid in reducing blood loss during total knee arthroplasty. J Arthroplasty 29: 1525-1527. [Crossref]

20. Reza Z, Moharamzadeh P, Alizadeharasi S,Ghasemi A,Saeedi M (2013) A new and rapid method for epistaxis treatment using injectable form of tranexamic acid topically: a randomized controlled trial. Am J Emerg Med 31: 1389-1392. [Crossref]

21. Zhang P, Liang Y, Chen P, Fang Y, He J, et al. (2016) Intravenous versus topical tranexamic acid in primary total hip replacement: A meta-analysis. Medicine (Baltimore) 95: e5573. [Crossref]

22. Sebastian F, Winter, Carlo S (2016) Jean W.Systemic and Topical Use of Tranexamic Acid in Spinal Surgery: A Systematic Review. Global Spine J 6: 284-295. [Crossref]

Copyright: (C2017 Yu kx and Bashyal SK. This is an open-access article distributed under the terms of the Creative Commons Attribution License, which permits unrestricted use, distribution, and reproduction in any medium, provided the original author and source are credited. 